\title{
SOLVING WATER RESOURCE SCHEDULING PROBLEM THROUGH AN IMPROVED ARTIFICIAL FISH SWARM ALGORITHM
}

\author{
He, L. X.* \& He, S. H.* \\ ${ }^{*}$ School of Civil Engineering, Tianjin University, Tianjin 300072, China \\ Hebei University of Engineering, Handan 056038, China \\ ${ }^{* *}$ College of Water Resource \& Hydropower, Chengdu 610065, China \\ E-Mail: helixinhbgc@163.com, heshancs@163.com
}

\begin{abstract}
In order to find a novel method for solving the water resources scheduling problem more effectively, the strategies of supply chain management were introduced and the calculation model was established. Then, the artificial fish swarm algorithm was employed to solve this problem. To avoid the premature defect of the basic artificial fish swarm algorithm, the improved adaptive algorithm was proposed. And engineering practice and comparison with other scheduling algorithms show the efficiency of the method. The study provides a novel method for the water resource scheduling.

(Received, processed and accepted by the Chinese Representative Office.)
\end{abstract}

Key Words: Water Sources Scheduling, Supply Chain Management, Artificial Fish Swarm Algorithm, Adaptive Strategy

\section{INTRODUCTION}

With social progress and economic development, water demand is growing. Water supply and demand contradictions have become increasingly prominent [1]. It is more and more important for the reasonable scheduling scheme of water resource [2-4].

The water resources scheduling problem centred in the reservoir was firstly proposed by Masse in 1940s [5, 6]. Over the past decades, with the hard work of the researchers, the study of water resources scheduling is gradually mature and more and more achievements are used to the engineering practice. Rockstrom introduced water resources scheduling in farm [7]. Arunkumar and Jothiprakash introduced chaotic evolutionary algorithms to multi-reservoir optimization [8]. Comair et al. proposed GIS-based system to guide water resources management [9]. Mortazavi et al. established multi-objective optimization model to schedule urban water resource [10]. Nouiri optimized the water resource management by using genetic algorithm [11]. In China, the electric power scheduling models of reservoir were established based on Markov theory and dynamic programming method, and were successfully used in the optimization scheduling of the hydropower station. Sun set up Soil and Water Assessment Tool (SWAT) model to assess crop yield and crop water productivity of the irrigation [12]. All these works promote the development of the related study. But, for the complex system of water resource allocation and scheduling, the traditional models and methods have these defects [13-15]:

(1) The traditional theories and methods of water resource allocation and scheduling often pay more attention to the supply and demand side. They usually consider the intermediate link from the technical feasibility viewpoint only, such as the size of the pipeline, amount and type of the facilities. And the demands of the users, the cost to efficiency ratio and the quality of service are rarely considered. In fact, these should not be ignored.

(2) The traditional methods usually use the cost to efficiency ratio to assess the efficiency of the allocation and scheduling. In reality, the allocation and scheduling is complex and often 
cover many fields with different targets. The traditional models are difficult to achieve the "optimum" goal of the system.

(3) Incomplete information is one of the bottlenecks in the complex system of water resource allocation and scheduling. Uncertainty will mislead the decision. The traditional methods usually ignore the information balance.

(4) In the contract design, the traditional methods are not corresponding with the fact.

We still have a long way to go in the selection of the scientific and reasonable water resources allocation and scheduling strategies and algorithms.

According to this, the optimization model based on supply chain management was established and the fish swarm algorithm was employed to settle the water resources scheduling problem. And according to the defects of fish swarm algorithm, the improved algorithm was proposed and employed to the water resources scheduling. Finally, the efficiency of the method was shown through the engineering application and the comparison with other scheduling algorithms. The difference between this work and the previous studies is that we introduced the supply chain management strategies and the artificial fish swarm algorithm was used to solve this problem. The significance is that this study proposed a novel method with higher efficiency for the water scheduling problem and it has a certain value in theory and practice for the water resource management.

\section{WATER RESOURCE SCHEDULING BASED ON SUPPLY CHAIN MANAGEMENT}

Now, the development of the water resource scheduling is from the "supply on demand", "technical-economic optimization" to the "control the demand by supply" and "communication and cooperation". Therefore, in order to achieve the scientific and reasonable water resources allocation and scheduling, the new effective supply chain management should be applied.

Supply chain management was firstly put forward in the enterprise management. In the 1980 s, it was used in some companies to realize the stable control of the production and obtain the stable workflow. During the decades' development, the supply chain management theory has been developed further and been used in many fields successfully $[16,17]$. Some large companies used the supply chain management theory successfully in practice and obtained remarkable economic benefits. In Europe, such as France, Germany, and Ireland, scholars and enterprise organizations also carried out the research of supply chain management and also made success. At the same time, the successful applications of supply chain management are numerous in China.

According to theory of supply chain, the direction of water resources allocation system can be regarded as regions interconnected by upstream and downstream nodes. Here, the water resource scheduling of some reservoir nodes in one area forms the supply chain management system, which can realize the maximization of water-retaining and regulating capability of the reservoir.

In the supply chain structure, the river basin including reservoir nodes is the core enterprise of a general supply chain system. The reservoir in the basin can be regarded as a distribution centre of water resources, and the water user surrounding the reservoir is equivalent to the consumer. The water resource scheduling based on supply chain management is a supply chain network structure including single product and many distribution centres. The supply chain structure of water resources scheduling of reservoirs is as follows. 


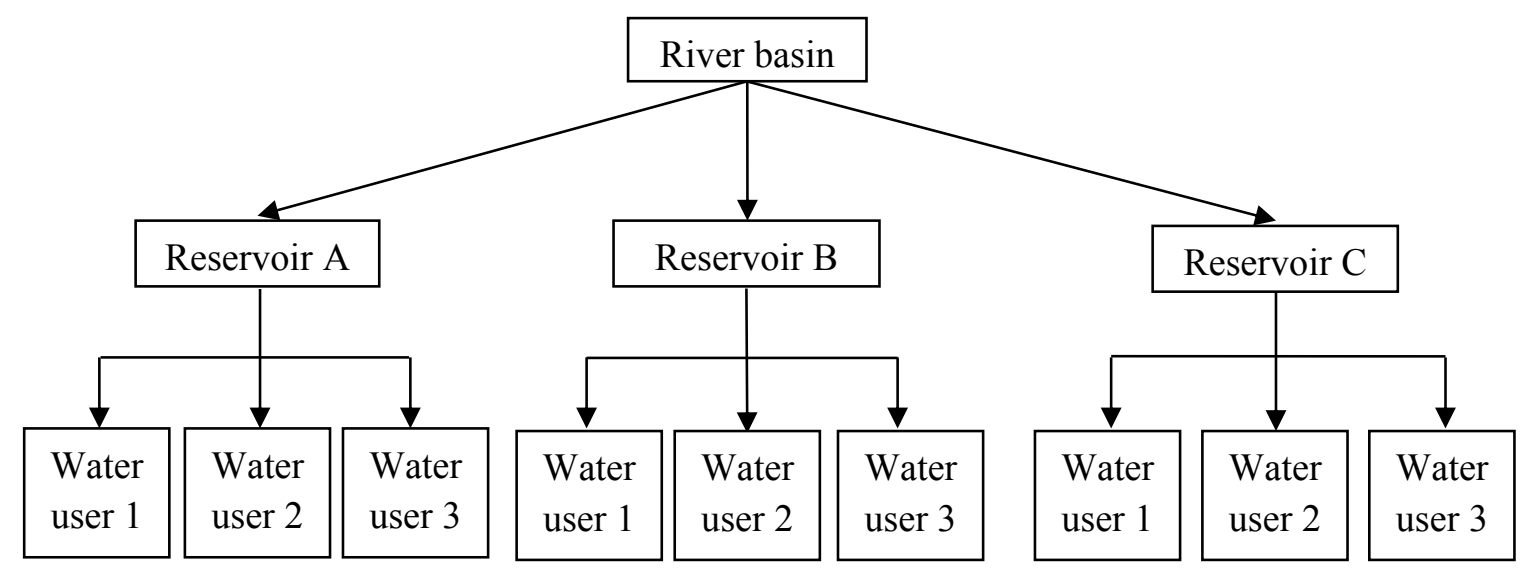

Figure 1: Supply chain structure of water resources scheduling.

Before building the water resource scheduling, the following assumptions are proposed:

(1) Regional water consumption only includes local existing regional water and the water supplying from reservoir.

(2) There is no cross between any reservoirs.

The scheduling model of water resources based on the supply chain can be expressed as follows.

$$
\begin{gathered}
q(t)=w(t)+u(t)-d(t) \\
F=\sum_{i=1} w^{*}[q(t)+S * Q(t)]^{2}+\left[\sum_{i=1} q(t)+\sum_{i=1} Q(t)\right]
\end{gathered}
$$

where, $t$ is the scheduling cycle. $q(t)$ is the water outflow of reservoir during $t . w(t)$ is water resource holding. $u(t)$ is the expected demand of water resource. $d(t)$ is the expectancy value of water consumption. $Q(t)$ is the water flow of reservoir from the current state to the safety level. $s$ is the reliability coefficient of reservoir, and the $w$ is the harmonic parameter of reservoir.

\section{AN IMPROVED ARTIFICIAL FISH SWARM ALGORITHM}

\subsection{Basic artificial fish swarm algorithm}

In recent years, biomimetic optimization algorithms have been widely used in various fields. The Artificial Fish Swarm Algorithm (AFSA) is a bionic random search optimization algorithm which simulates the feeding, clusters, and rear-ends behaviours of fish [18]. The state of the artificial fish can be expressed as $X=\left(x_{1}, x_{2}, \ldots, x_{n}\right),(i=1,2, \ldots, n)$, and the current location of the food concentration is $Y=f(x)$. Where, $Y$ and $X$ are the corresponding objective function values respectively. $d_{i j}=\left\|x_{i}-x_{j}\right\|$ is the artificial fish's distance. $\delta$ is congestion factor, and the number of fish scale is $N$. The artificial fish swarm algorithm is a random optimization algorithm with good global search capability and less demanding on the sensitivity of various parameters. And the algorithm is easy to implement. At present, the algorithm has been applied in many fields successfully. But with the disadvantages of premature and lower optimization accuracy, the quality and efficiency of the algorithm are affected. To overcome these shortcomings, the following strategy was employed.

\subsection{Improvement}

To overcome the shortcomings above, the chaotic early initialization was employed to improve the quality of group solutions of artificial fish. And the inertia adjustment strategy was used to dynamically adjust the visual and step of the artificial fish. 
3.2.1 Degree of premature convergence of artificial fish

Here, if $Y_{a v g}$ is the current average value of the objective function, then

$$
\mathrm{Y}_{\text {avg }}=\frac{1}{N} \sum_{i=1}^{n} Y_{i}
$$

where, $Y_{i}$ is the artificial fish in the current iteration. The optimal objective function value of artificial fish is $Y_{g}$, and if the objective function value is better than $Y_{\text {avg }}$, and the average value is $Y_{\text {avg }}^{*}$, defined

$$
\phi=\left|Y_{g}-Y_{\text {avg }}^{*}\right|
$$

$\varphi$ can be used to evaluate the extent of premature convergence. Smaller $\varphi$ means the greater chance to premature convergence.

\subsubsection{Adaptive strategy of the visual and step adjustment}

In the artificial fish swarm algorithm, when the optimal objective function value does not change for a long time, the step size should be adjusted adaptively to avoid premature convergence.

If the objective function value is $Y_{i}$, the adjustment method is as follows.

(1) $Y_{i}$ is better than $Y_{\text {avg }}^{*}$

$$
\text { Step }=\text { Step }-\left(\text { Step }_{-} \text {Step }_{\text {min }}\right) \cdot\left|\frac{Y_{i}-Y^{*}{ }_{\text {avg }}}{Y_{g}-Y^{*}{ }_{\text {avg }}}\right|
$$

(2) $Y_{i}$ is better than $Y_{\text {avg }}$ but inferior to $Y_{a v g}^{*}$

$$
\text { Step }=\text { Step }_{\text {min }}+\left(\text { Step }_{\max }-\text { Step }_{\min }\right) \times \frac{1+\cos ((\text { iter }-1) \pi /(\text { MaxStep }-1))_{2}}{2}
$$

where, Step max $_{\text {ix }}$ is the largest step of search, Step $\min$ is the smallest step at the end of search, iter is the iteration time, MaxStep is the maximum number of allowed iterations.

(3) $Y_{i}$ is inferior to $Y_{a v g}$

$$
\text { Step }=1.5-\frac{1}{1+K_{1} \cdot \exp \left(-K_{2} \cdot \varphi\right)}
$$

Here, $K_{1}=1.5, K_{2}=5$. If the algorithm does not fall into stagnation, the value of $\varphi$ will increase, and the algorithm can reduce the step of artificial fish and strengthen local optimization [18]. The value of $\varphi$ will be smaller before the algorithm traps into local optimal, which can strengthen the searching ability of the artificial fish.

And the field of view of the artificial fish is:

$$
\text { Visual }=8 \text { Step }
$$

\subsubsection{Initial group solution}

In order to produce higher quality artificial fish, the Logistic equation was used to obtain initial solution.

$$
X_{k+1}=\mu X_{k}\left(1-X_{k}\right)
$$

$X_{k} \in[0,1]$ and $\mu$ is a control parameter, $\mu=4$.

The framework of the algorithm is shown in Fig. 2.

\subsection{Simulation experiments}

In order to verify the efficiency of the improved algorithm, the following simulations were carried out. 


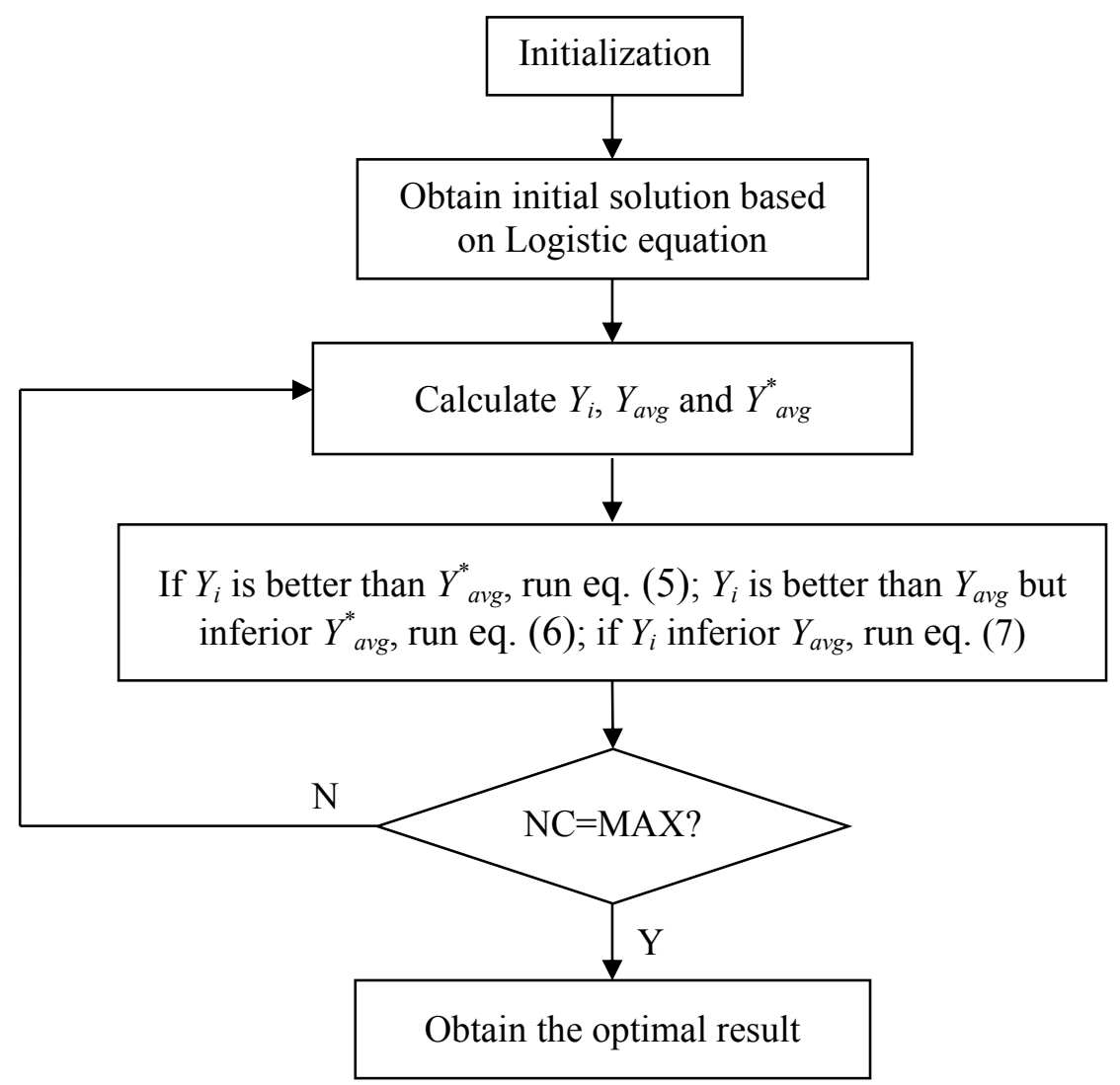

Figure 2: The framework of the improved algorithm.

\subsubsection{Test function}

The test function and its three-dimensional image were as follows.

$$
F_{1}=-\frac{\sin ^{2} \sqrt{x^{2}+y^{2}}-0.5}{\left(1+0.001\left(x^{2}+y^{2}\right)\right)^{2}}+0.5, x, y \in[-100,100]
$$

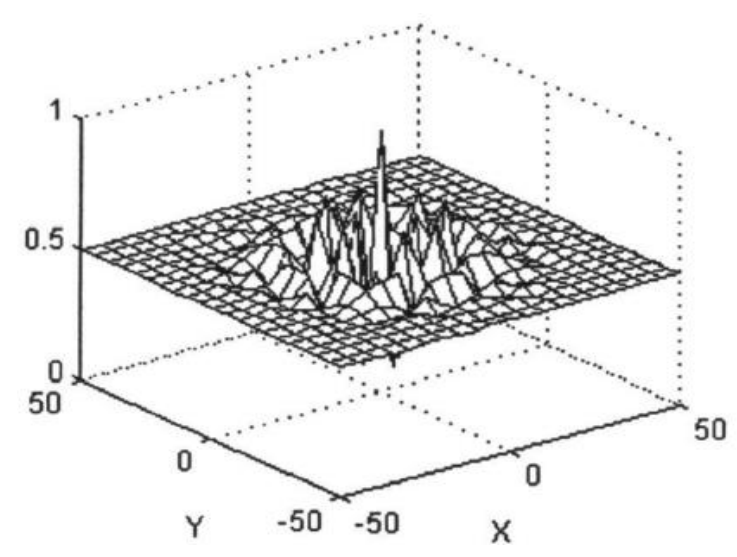

Figure 3: The three-dimensional image of function.

The function $F_{1}$ has many extreme points, and the minimal value is zero. The function has a circle valley near minimum value 0.0024559 . So, many traditional methods are easy to fall into local extreme. The basic artificial fish swarm algorithm and the improved artificial fish swarm algorithm we proposed were compared on this function. The parameters setting: MaxStep $=100, N=10$, Trynumber $=60, \delta=0.618$, Visual $=8$ and Step $=0.6$. First, artificial fish were distributed in initial solution space, after a certain number of iterations, if the 
current optimal solution of the objective function is not changed, change the step length adaptively. Then, compare the current average value of feasible solution and the current optimal solution of the objective function, and the artificial fish continue to search the solution space. The results are shown in the Fig. 4.

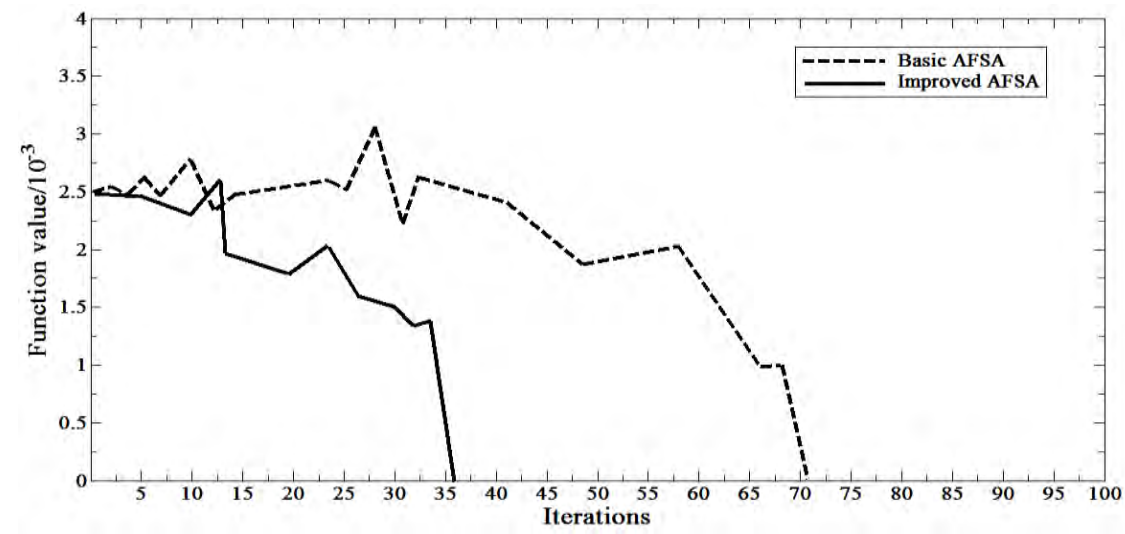

Figure 4: Performance comparison between basic and improved artificial fish swarm algorithm.

From the comparison, we can know that the improved artificial fish swarm algorithm reached the optimal solution at $36^{\text {th }}$ iteration, the basic artificial fish swarm algorithm got the optimal solution at $71^{\text {st }}$ iteration, and the iteration process of the improved algorithm is more stable. It is obvious that because of the improvement of initialization and the adaptive strategy of the visual and step adjustment, the improved artificial fish swarm algorithm is more likely to obtain the better solution.

\subsubsection{TSP}

We compared the performance of the algorithms on the Travelling Salesman Problem (TSP) Berlin 52 and Att532. As a combinatorial optimization problem, TSP was usually used to verify the performance of different algorithms. On the TSP Berlin 52, the parameters setting of artificial fish swarm algorithm is: MaxStep $=100, N=10$, Trynumber $=20, \delta=0.618$, Visual $=8$ and Step $=0.6$. The experimental results are shown in Table I and Fig. 5.

Table I: Algorithm performance comparison.

\begin{tabular}{|c|c|c|c|}
\hline Algorithm & Optimal solution known & Average solution & Iterations \\
\hline $\begin{array}{c}\text { Basic artificial fish } \\
\text { swarm algorithm }\end{array}$ & \multirow{2}{*}{7542} & 8044.62 & 77 \\
\cline { 1 - 3 } $\begin{array}{c}\text { Improved artificial fish } \\
\text { swarm algorithm }\end{array}$ & \multirow{2nyy}{nnyy}{} & 7655.89 & 63 \\
\hline
\end{tabular}

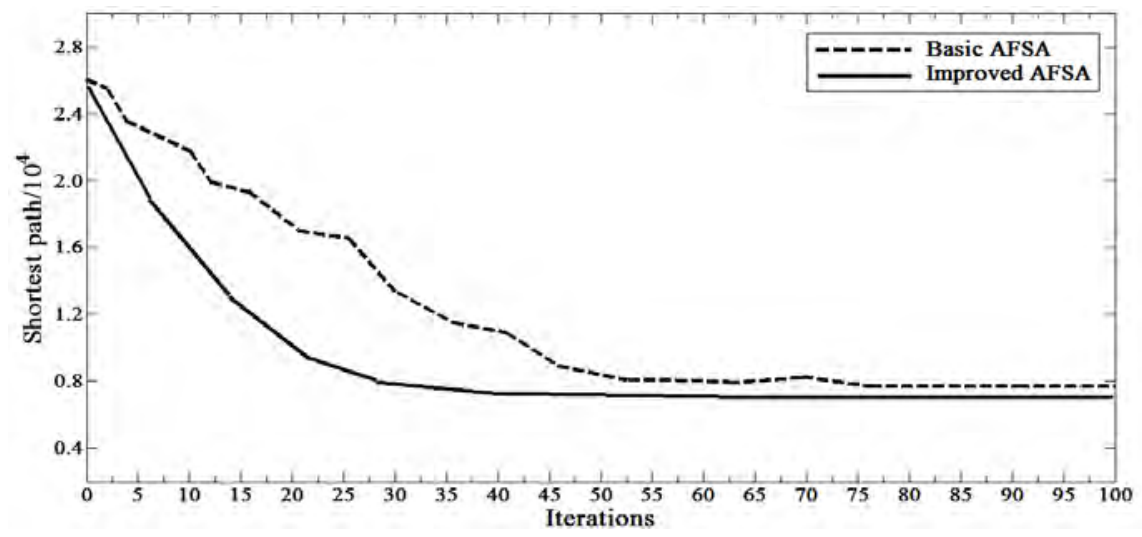

Figure 5: Performance comparison on TSP Berlin 52. 
The improved algorithm we proposed obtained the optimal solution 7655.89 at $63^{\text {rd }}$ iteration, and the basic artificial fish swarm algorithm achieved the optimal solution 8044.62 at $77^{\text {th }}$ iteration. The improved algorithm is more effective.

On the TSP Att532, the improved algorithm was compared with basic artificial fish swarm algorithm and the Ant Colony Optimization (ACO) algorithm. The parameters setting of artificial fish swarm algorithm: MaxStep $=1000, N=100$, Trynumber $=200, \delta=0.618$, Visual $=8$ and Step $=0.6$. The parameters setting of ACO: $\alpha=0.1, \beta=2, \rho=0.5, Q=0.5$, the maximum number of iterations is 600 . The experimental results are shown in Table II and in Fig. 6.

Table II: Algorithm performance comparison.

\begin{tabular}{|c|c|c|c|}
\hline Algorithm & Optimal solution known & Average solution & Iterations \\
\hline Artificial fish swarm algorithm & \multirow{3}{*}{27686.5} & 27789.5 & 647 \\
\hline $\begin{array}{l}\text { Improved artificial fish swarm } \\
\text { algorithm }\end{array}$ & & 27694.3 & 534 \\
\hline Ant colony optimization & & 27708.6 & 600 \\
\hline
\end{tabular}

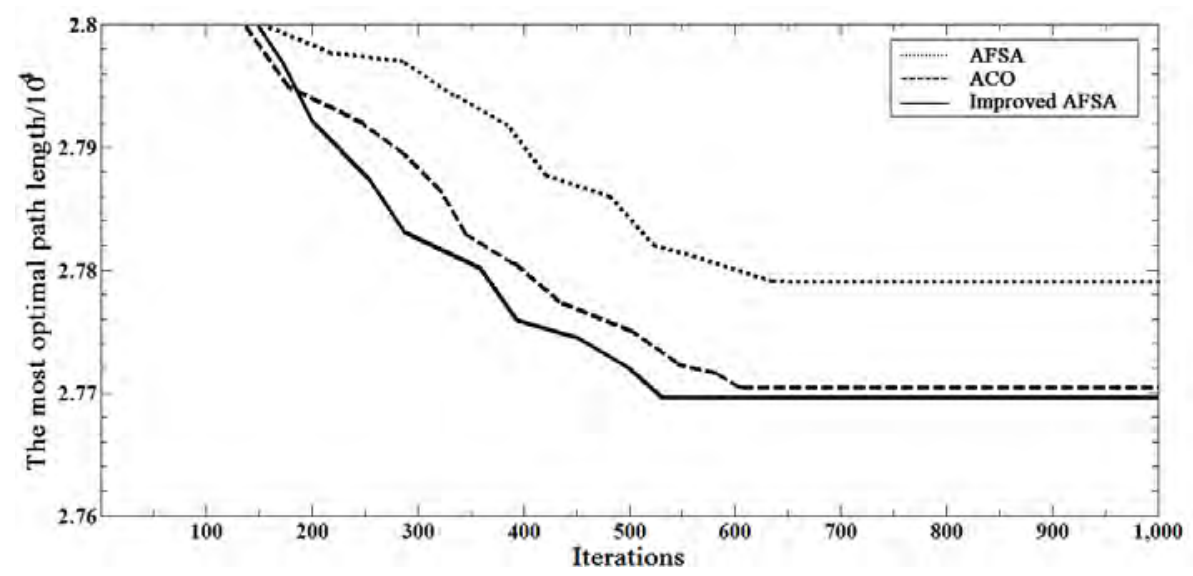

Figure 6: TSP Att532 iterative curve.

The improved algorithm we proposed achieved the optimal solution 27694.3 at $534^{\text {th }}$ iteration, and the basic artificial fish swarm algorithm achieved the optimal solution 27789.5 at $647^{\text {th }}$ iteration. The ant colony optimization achieved it optimal 27708.6 at $600^{\text {th }}$ iteration. On this question, the improved artificial fish swarm algorithm proposed here is better than other two algorithms.

\section{WATER RESOURCES SCHEDULING OPTIMIZATION THROUGH AN IMPROVED AFSA}

After the comparison, the method was used to solve the water resources scheduling problem. And the reservoirs of Hebei and Liaoning province in China were analysed.

\subsection{Water resources scheduling of reservoirs in Hebei province}

The reservoir network is shown in Fig. 7. It is a third-grade reservoir, and it is made up of four reservoir nodes [19]. Node $A$ was a first-grade reservoir, $B$ and $C$ were second-grade reservoir, and $D$ was the objective reservoir. The data of four nodes are shown in Table III.

Suppose the maximum generating capacity is the objective function, the storage capacity, the generating capacity, and the reservoir availability are the constraint conditions. Then the improved artificial fish swarm algorithm, the basic artificial fish swarm algorithm, the improved ant colony optimization algorithm and the conventional scheduling method were 
used on this question. The parameters setting of AFSA: MaxStep $=100, N=10$, Trynumber $=$ $20, \delta=0.618$, Visual $=8$ and Step $=0.6$. The parameter settings of the improved ant colony optimization algorithm and the conventional scheduling method are same as in [19]. The comparison results are shown in Figs. 8 and 9.

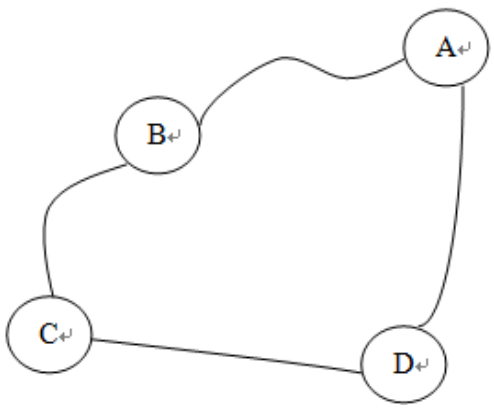

Figure 7: The third-grade reservoir.

Table III: Relevant data of four nodes.

\begin{tabular}{|c|c|c|c|}
\hline Number & $\begin{array}{c}\text { Storage capacity } \\
\left(\text { hundred million } \mathrm{m}^{3} \text { ) }\right.\end{array}$ & $\begin{array}{c}\text { Generating capacity } \\
(\text { million } \mathrm{kWh} \text { ) }\end{array}$ & $\begin{array}{c}\text { Reliability } \\
\text { parameter }\end{array}$ \\
\hline A & 12.02 & 1.30 & 0.78 \\
\hline B & 9.04 & 0.80 & 0.76 \\
\hline C & 9.50 & 1.10 & 0.67 \\
\hline D & 12.02 & 2.30 & 0.86 \\
\hline
\end{tabular}

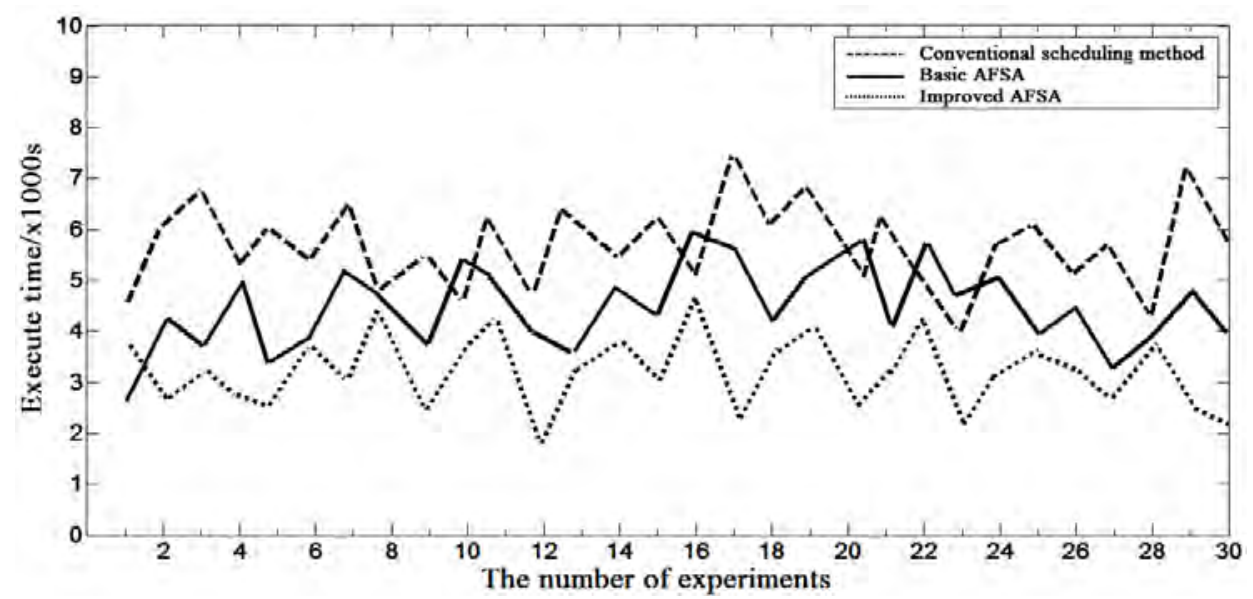

Figure 8: Comparison of execute time.

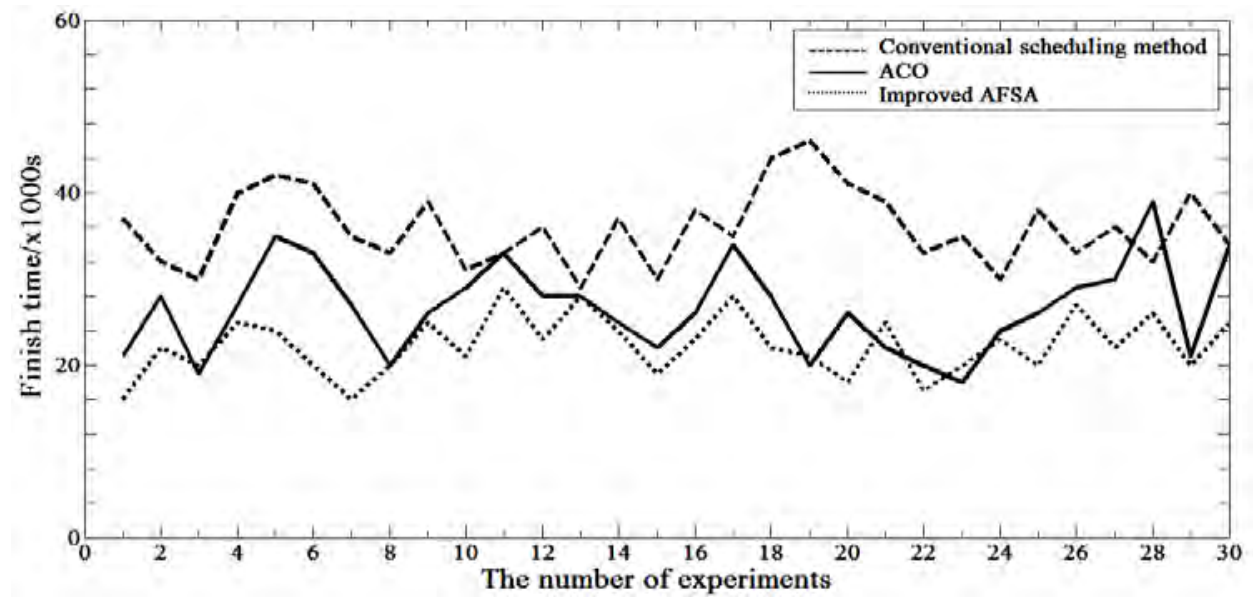

Figure 9: Comparison of finish time. 
Figs. 8 and 9 showed the better performance of the improved artificial fish swarm algorithm on this question.

\subsection{Water resources scheduling of reservoirs in Liaoning province}

Then, the algorithm was employed to the water resources scheduling of reservoirs in Liaoning province. The reservoir system is shown in Fig. 10. It is made up of five reservoir nodes [19]. The system is established based on supply chain management theory.

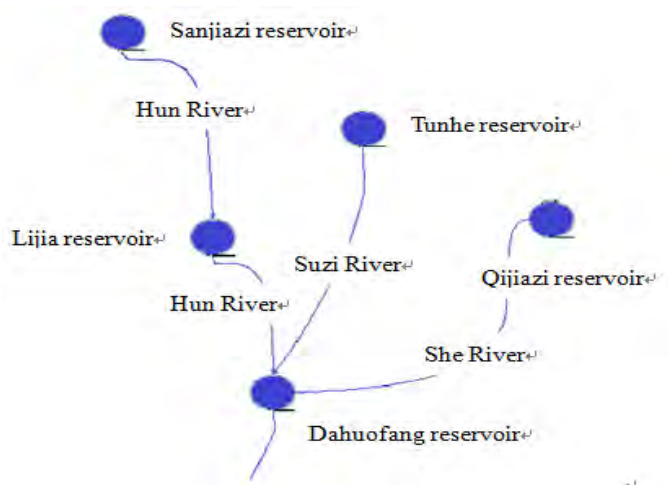

Figure 10: Dahuofang reservoir system.

The parameters of artificial fish swarm algorithm: MaxStep $=100, N=10$, Trynumber $=20$, $\delta=0.618$, Visual $=8$ and Step $=0.6$. The parameter settings of the improved ant colony optimization algorithm and the conventional scheduling method are same as in [19]. The maximum generating capacity is the objective function. The storage capacity, the generating capacity, and the reservoir availability are the constraint conditions. For a reservoir, its goal function is as follows.

$$
F=\sum_{i=1} w^{*}\left[q(t)+S^{*} Q(t)\right]^{2}+\left[\sum_{i=1} q(t)+\sum_{i=1} Q(t)\right]
$$

where, $t$ is the scheduling cycle. $q(t)$ is the water outflow of reservoir during $t . Q(t)$ is the water flow of reservoir from the current state to the safety level. $s$ is the reliability coefficient of the reservoir, and $w$ is the harmonic parameter of the reservoir. The relevant data of five nodes are shown in Table IV.

Table IV: The relevant data of five reservoirs.

\begin{tabular}{|c|c|c|c|c|c|c|}
\hline \multirow{2}{*}{ Reservoirs } & \multicolumn{2}{|c|}{$\begin{array}{c}\text { Reservoir inflow } \\
\left(\text { hundred million } \mathrm{m}^{3} \text { ) }\right.\end{array}$} & \multicolumn{2}{c|}{$\begin{array}{c}\text { Reservoir outflow } \\
\text { (hundred million } \mathrm{m}^{3} \text { ) }\end{array}$} & \multicolumn{2}{c|}{$\begin{array}{c}\text { Generating capacity } \\
\text { (million } \mathrm{kWh} \text { ) }\end{array}$} \\
\cline { 2 - 7 } & $\begin{array}{c}\text { Ant colony } \\
\text { optimization }\end{array}$ & $\begin{array}{c}\text { Improved } \\
\text { artificial } \\
\text { fish swarm } \\
\text { algorithm }\end{array}$ & $\begin{array}{c}\text { Ant colony } \\
\text { optimization }\end{array}$ & $\begin{array}{c}\text { Improved } \\
\text { artificial } \\
\text { fish swarm } \\
\text { algorithm }\end{array}$ & $\begin{array}{c}\text { Ant colony } \\
\text { optimization }\end{array}$ & $\begin{array}{c}\text { Improved } \\
\text { artificial } \\
\text { fish swarm } \\
\text { algorithm }\end{array}$ \\
\hline Sanjiazi & 4.362 & 4.362 & 4.153 & 4.223 & 8.0 & 8.13 \\
\hline Tunhe & 4.06 & 4.06 & 3.87 & 3.87 & 11.0 & 11.0 \\
\hline Qjiazi & 7.31 & 7.31 & 6.84 & 6.99 & 13.0 & 13.29 \\
\hline Lijia & 3.13 & 3.83 & 3.05 & 3.41 & 10.0 & 11.18 \\
\hline Dahuofang & 11.69 & 12.27 & 11.66 & 12.1 & 12.64 & 13.12 \\
\hline
\end{tabular}

From the above experimental results, we can know that through optimizing by improved artificial fish swarm algorithm, the generating capacity was improved by $4 \%$. The comparison results between the ant colony algorithm, conventional scheduling method and the improved artificial fish swarm algorithm were shown in Figs. 11 and 12. 


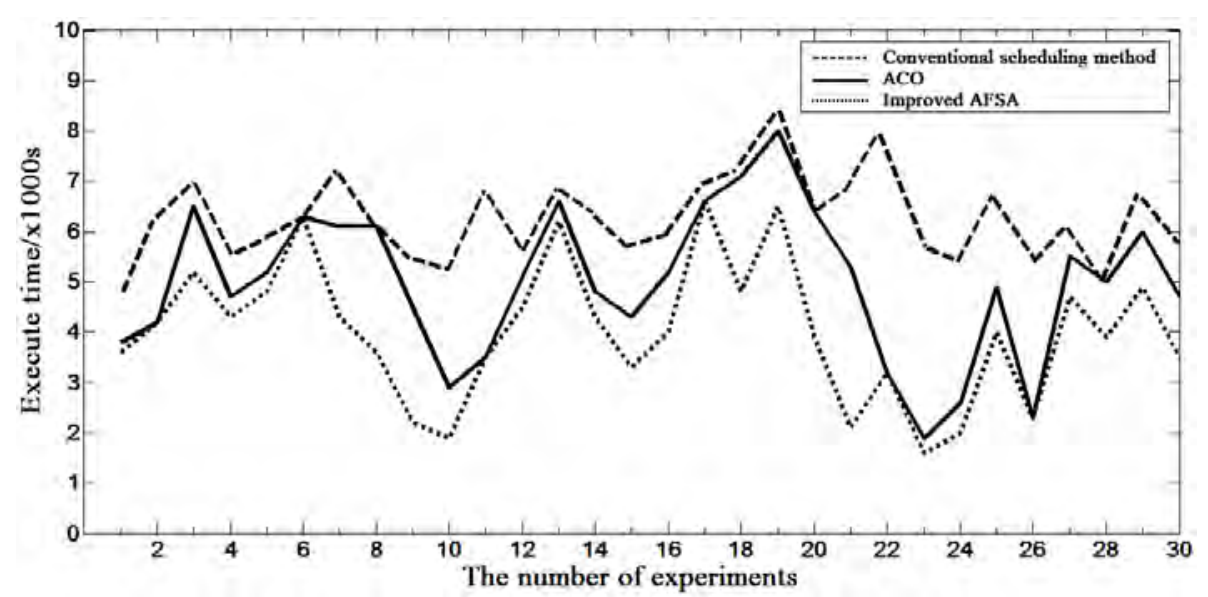

Figure 11: Comparison of execute time.

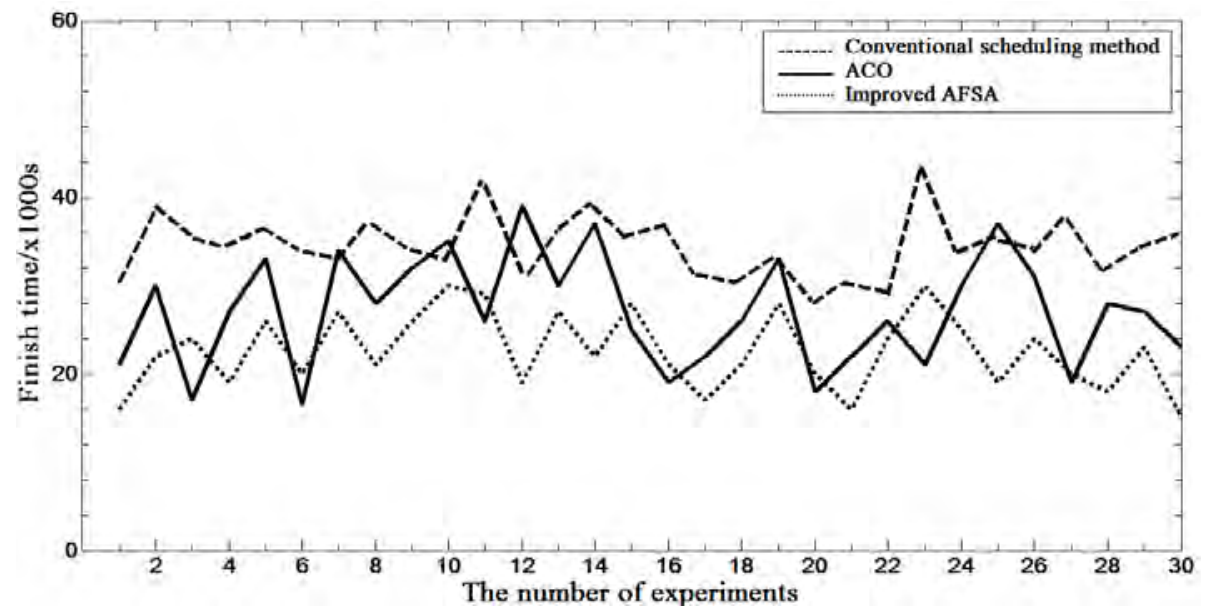

Figure 12: Comparison of finish time.

Figs. 11 and 12 showed the performance of the improved artificial fish swarm algorithm is better than other two algorithms.

Through the simulating above, we can know that the improved artificial fish swarm algorithm has good applicability to deal with this complex problem. Simply setting a small number of fishes can achieve better computational accuracy.

\section{CONCLUSIONS}

Now, the water supply and demand contradictions have become increasingly prominent. The water resources optimization scheduling is more and more important. In order to find a more effective scheduling method, we introduced the supply chain management strategies and the artificial fish swarm algorithm to solve this problem. To overcome the stagnation of the basic algorithm, the adaptive artificial fish swarm algorithm was proposed and introduced into the water resources scheduling. The engineering application and the comparisons with other algorithms showed the feasibility and effectiveness of improved artificial fish swarm algorithm. This study proposed a novel solution method for the water sources scheduling problem.

The work has a certain value in theory and practice for the water resource management. But, it is just a beneficial trial. In the future works, we will focus on the following:

(1) Here, the static scheduling of water resource was just considered, the methods for the dynamic scheduling of the water resource should be studied further. 
(2) We just employed the chaotic early initialization and the inertia adjustment strategy to improve the basic artificial fish algorithm. These improvements overcome the premature defect of basic artificial fish algorithm. But, it is just a trial. In the control of the premature, we still have a long way to go, especially, the initialization methods and parameter setting. In the next study, we will focus on these questions and propose more improvements to obtain more effective algorithms.

\section{ACKNOWLEDGEMENT}

The work was supported by the fund of the National Youth Social Science Foundation of China (CIA 060076) and the Talents Program of Hebei Province (2011-55).

\section{REFERENCES}

[1] De Graaf, I. E. M.; van Beek, L. P. H.; Wada, Y.; Bierkens, M. F. P. (2014). Dynamic attribution of global water demand to surface water and groundwater resources: Effects of abstractions and return flows on river discharges, Advances in Water Resources, Vol. 64, 21-33, doi:10.1016/ j.advwatres.2013.12.002

[2] Chou, F. N. F.; Lee, H.-C.; Yeh, W. W. G. (2013). Effectiveness and efficiency of scheduling regional water resources projects, Water Resources Management, Vol. 27, No. 3, 665-693, doi:10.1007/s11269-012-0208-9

[3] Reca, J.; García-Manzano, A.; Martínez, J. (2013). Optimal pumping scheduling for complex irrigation water distribution systems, Journal of Water Resources Planning and Management, Vol. 140, No. 5, 630-637, doi:10.1061/(ASCE)WR.1943-5452.0000360

[4] Hassanzadeh, E.; Elshorbagy, A.; Wheater, H.; Gober, P. (2014). Managing water in complex systems: An integrated water resources model for Saskatchewan, Canada, Environmental Modelling \& Software, Vol. 58, 12-26, doi:10.1016/j.envsoft.2014.03.015

[5] Maier, H. R.; Kapelan, Z.; Kasprzyk, J.; Kollat, J.; Matott, L. S.; Cunha, M. C.; Dandy, G. C.; Gibbs, M. S.; Keedwell, E.; Marchi, A.; Ostfeld, A.; Savic, D.; Solomatine, D. P.; Vrugt, J. A.; Zecchin, A. C.; Minsker, B. S.; Barbour, E. J.; Kuczera, G.; Pasha, F.; Castelletti, A.; Giuliani, M.; Reed, P. M. (2014). Evolutionary algorithms and other metaheuristics in water resources: Current status, research challenges and future directions, Environmental Modelling \& Software, Vol. 62, 271-299, doi:10.1016/j.envsoft.2014.09.013

[6] Li, Y.-C.; Zhao, L.; Suo, J.-J. (2015). Comprehensive assessment of marine ecological environment based on entropy weight model, Polish Journal of Environmental Studies, Vol. 24, No. 1, 151-155

[7] Rockstrom, J. (2000). Water resources management in smallholder farms in Eastern and Southern Africa: An overview, Physics and Chemistry of the Earth, Part B: Hydrology, Oceans and Atmosphere, Vol. 25, No. 3, 275-283, doi:10.1016/S1464-1909(00)00015-0

[8] Arunkumar, R.; Jothiprakash, V. (2013). Chaotic evolutionary algorithms for multi-reservoir optimization, Water Resources Management, Vol. 27, No. 15, 5207-5222, doi:10.1007/s11269013-0463-4

[9] Comair, G. F.; McKinney, D. C.; Maidment, D. R.; Espinoza, G.; Sangiredy, H.; Fayad, A.; Salas, F. R. (2014). Hydrology of the Jordan river basin: A GIS-based system to better guide water resources management and decision making, Water Resources Management, Vol. 28, No. 4, $933-$ 946, doi:10.1007/s11269-014-0525-2

[10] Mortazavi-Naeini, M.; Kuczera, G.; Cui, L. (2014). Application of multi objective optimization to scheduling capacity expansion of urban water resource systems, Water Resources Research, Vol. 50, No. 6, 4624-4642, doi:10.1002/2013WR014569

[11] Nouiri, I. (2014). Multi-objective tool to optimize the water resources management using genetic algorithm and the Pareto optimality concept, Water Resources Management, Vol. 28, No. 10, 2885-2901, doi: 10.1007/s11269-014-0643-X 
[12] Sun, C.; Ren, L. (2014). Assessing crop yield and crop water productivity and optimizing irrigation scheduling of winter wheat and summer maize in the Haihe plain using SWAT model, Hydrological Processes, Vol. 28, No. 4, 2478-2498, doi:10.1002/hyp.9759

[13] Mirchi, A.; Madani, K.; Watkins Jr., D.; Ahmad, S. (2012). Synthesis of system dynamics tools for holistic conceptualization of water resources problems, Water Resources Management, Vol. 26, No. 9, 2421-2442, doi:10.1007/s11269-012-0024-2

[14] Kalbacher, T.; Delfs, J.-O.; Shao, H.; Wang, W.; Walther, M.; Samaniego, L.; Schneider, C.; Kumar, R.; Musolff, A.; Centler, F.; Sun, F.; Hildebrandt, A.; Liedl, R.; Borchardt, D.; Krebs, P.; Kolditz, O. (2012). The IWAS-toolbox: Software coupling for an integrated water resources management, Environmental Earth Sciences, Vol. 65, No. 5, 1367-1380, doi:10.1007/s12665$\underline{011-1270-\mathrm{y}}$

[15] Chen, C.; Huang, G. H.; Li, Y. P.; Zhou, Y. (2013). A robust risk analysis method for water resources allocation under uncertainty, Stochastic Environmental Research and Risk Assessment, Vol. 27, No. 3, 713-723, doi:10.1007/s00477-012-0634-5

[16] Alfalla-Luque, R.; Medina-Lopez, C.; Schrage, H. (2013). A study of supply chain integration in the aeronautics sector, Production Planning \& Control: The Management of Operations, Vol. 24, No. 8-9, 769-784, doi:10.1080/09537287.2012.666868

[17] Bonabeau, E.; Theraulaz, G. (2000). Swarm smarts, Scientific American, Vol. 282, No. 3, 72-79, doi: $10.1038 /$ scientificamerican0300-72

[18] Qu, L. D.; He, D. X. (2010). Novel artificial fish-school algorithm based on chaos search, Computer Engineering and Applications, Vol. 46, No. 22, 40-42

[19] Jiang, L. (2012). An implement of improved ant colony optimization algorithm and its application in water resources scheduling, Master Dissertation, Jilin University 